\title{
SURVEY ON LEARNING CONCEPTS APPLYING CREATIVITY METHODS IN EDUCATION AND INDUSTRY
}

\author{
Marc NUTZMANN ${ }^{1}$, Thorsten SAUER ${ }^{1}$, Markus VOß ${ }^{2}$ and Hulusi BOZKURT ${ }^{2}$ \\ ${ }^{1}$ DHBW Baden-Wuerttemberg Cooperative State University, Friedrichshafen, Germany \\ ${ }^{2}$ DHBW Baden-Wuerttemberg Cooperative State University, Mannheim, Germany
}

\begin{abstract}
This paper reflects experiences in teaching creativity methods, e.g. brainwriting, brainstorming or TRIZ. It compares 'classic' lectures where methods are described by the lecturer ('teacher-centred' learning) to a concept of specific exercises, where students are asked to apply the methods in teams. This rather 'student centred' learning concept allocates time to discuss the methods and experiences made by applying them in class. At a later point in the learning process students get more information, reflective views and discussion points through an e-learning platform. In order to evaluate the students' perception of the learning concepts a questionnaire-based survey was conducted among altogether 150 students in four courses, three bachelor courses of different engineering programmes and a master course. The survey evaluates 1 . which learning concept according to the students helps to broaden systematic and methodical creativity skills best, 2 . which creativity methods students consider to be applicable in industry and 3. if these methods are already applied in the students' companies. The latter point can be analysed as every student at DHBW Baden-Wuerttemberg Cooperative State University compulsorily has a contract with a company and spends half of the studies in on projects in industry. Thus, the paper gains valuable insights into approximately hundred companies of different branches and sizes. Besides the conceptual description of the learning approach on methodical skills and the survey itself, the paper also furnishes an overview of best-practice examples that aim at helping students to engage with the engineering design process, focussing in particular on supporting methods and their application in industry.
\end{abstract}

Keywords: Student-centred learning, creativity methods, e-learning, blended learning

\section{INTRODUCTION}

Mechanical engineering students acquire knowledge and skills in engineering design through several courses reaching from learning how to setup technical design drawings, CAD-courses, several courses dealing with machine elements and numerical analysis (FEM). In mechanical engineering the percentage of courses on engineering design covers, depending on the specific studies, from $10 \%$ in production engineering to $25 \%$ in engineering design of the overall credits. At the DHBW engineering design students are additionally encountered with a course on systematic approaches and processes (e.g. time to market process, agile project management, design thinking), diverse methods to facilitate and strengthen efficiency in the design and development process. In the last few years new concepts of education were implemented: Additive manufacturing allows the integration of prototyping, e-learning platforms allow the placement of pre- and post-educational content (blended learning) and therefore support open cooperation between students and lecturer [1].

\section{OBJECTIVE OF THE SURVEY}

The survey is carried out in four courses, three bachelor courses of different year and a master course, in which altogether 150 students were enrolled. The survey evaluates among the students which education concept helps to broaden systematic and methodical creativity skills best, which creativity methods are found to be applicable in industry and if these methods are already applied in the student's partner company. The questionnaire was setup and distributed to the students that have 
attended the course continuously. The questionnaire consisted of 20 questions, starting off with questions concerning the context, e.g. students partner company (size, systematic and structural setup) and the application of processes (traditional processes like stage-gate System [2], [3], alternative management processes, like design thinking or agile process management), but also concerning interdisciplinary and voluntary team building provision within the company. After that an evaluation of methods that have been introduced and experienced during the lecture and the student's reflection on applicability in industry are questioned. A set of creativity methods, in particular brainwriting and TRIZ, were experienced in exercises, brainstorming, morphologic box and other methods were taught in teacher-centred lectures. The conceptual difference allows to validate teaching effects, the student's gain in knowledge on methods and the willingness to apply methods in industry. Finally an evaluation of different learning concepts is implemented and the support of the e-learning content is questioned.

The objective of the survey can be concluded to the following points:

- Clarification of student's context (study year, industrial experience etc.).

- Evaluation of the methods taught in the lecture.

- Evaluation of the concept of teaching/ learning, especially creativity methods: Experience by exercises (student-centred learning) and group work versus traditional lecture (teacher-centred lecture).

- Declaration/ willingness to apply the methods in projects and industry.

- Some methods help to foster the design and development process even though they're not typical engineering design tools, e.g. portfolio analysis, risk analysis, methods to integrate customer and users. Are these methods recognised by the students?

\section{LECTURE CONTENTS, CONCEPT AND COURSE DETAILS}

The lecture "Engineering Design and Development" consists of 24 hours of lecture time distributed over 11 weeks. In week twelve a written exam takes place where the lecture contents are tested - some of the questions not only asking to repeat learning contents but also testing the ability to transfer the knowledge to a setup problem. This aspect is later needed to reflect some of the students answers in the survey concerning the applicability of some of the methods. The setup of the lecture is summarised in Figure 1.

\begin{tabular}{|c|c|c|}
\hline 01 & Introduction & L \\
\hline 02 & Creativity and Innovation & L, P \\
\hline 03 & Development Processes I: Basics & L \\
\hline 04 & Development Processes II: Customer and User Integration & $\mathrm{L}$ \\
\hline 05 & Brainstorming Session & $P$ \\
\hline 06 & Group presentations & $P$ \\
\hline 07 & Project opportunities and Strategies & L \\
\hline 08 & More methods/ tools & L, P \\
\hline 09 & Summarization of educational objectives & L \\
\hline
\end{tabular}

L: Lecture; P: Practical Work/ Exercise

Figure 1. contents of the lecture engineering design and development

Some of the lectures consist of the traditional way of "teacher-centred" teaching, especially on processes, investigative and empiric methods. But especially creativity methods, defined as intuitive methods in figure 2, are predestined to be taught in exercises and group work. This allows students to experience the methods, it allows the lecturer to address typical advantages and disadvantages by observation and pointing out typical systematics. It also values higher motivation for creativity workshops and inhibitions can be reduced.

A direct knowledge transfer of good practice applying methods can be noticed. By applying the 6-3-5 Brainwriting (Method 635) [4], [5] students learn about an alternative to the mostly already known and 
experienced brainstorming method [6]. As we know brainstorming works with people that have an open mind-set, constructive and collaborative personalities [4], [7], [8] - especially found with students. Thus, often this culture is not found in companies [9]. This is also recognised by the students and as we see later, the survey confirms this, too. Compared to brainstorming the alternative brainwriting has the advantage that a lot of ideas (theoretically 108 ideas), can be generated within only 30 minutes [4], [5], [9]. For the lecturer Method 635 is easy to handle in a two-hour lecture including discussions and reflection.

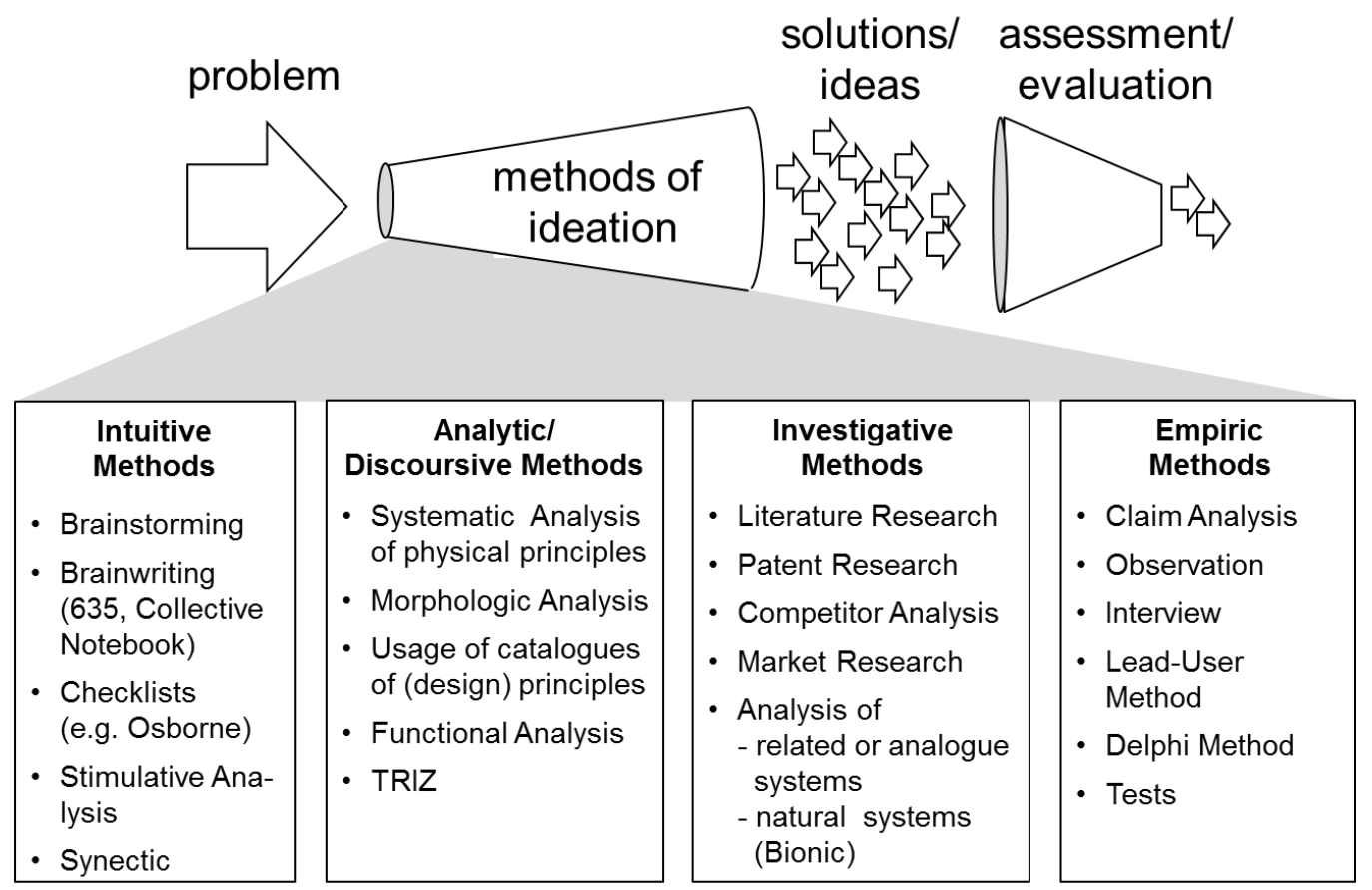

Figure 2. methods of engineering design and development

The integration or application of methods in a development process and a systematic process is also an objective of the lecture. This can only be reached through the reflective view on the complete lecture course, often found to be challenging for most post-graduate students. Therefore, later in the lecture, after experiencing additional methods and processes, the students are given a group work. The group work allows them to team-up, choose a free problem in the group and work their way through a development process. In a down scaled way the groups work their way through the first two to three typical design and development process phases, from problem definition to the concept phase and design phase. Optional the groups can also choose the management process system: The traditional development process according to VDI2221 [2] or stage-gate system by Cooper [3], alternatively agile process management, design thinking or if applicable business model innovation. Only requirements given to solve their design and development problem was to set up a user/ customer requirement list (specification sheet), a small market research to address the market need, performing of minimum two creativity methods, assessment of the found ideas and derive a concept to solve the problem. A prototyping was addressed to be desirable but not a "must"-requirement. The groups were asked to present their results in a five to ten-minute presentation to the class. A documentation of the results was asked to be uploaded in the e-learning platform. The task is fairly free but allows to set up a small project, work through it systematically in a team and allowed to set the methods and processing into a competitive context.

The traditional way of design and development processing (VDI2221 and Cooper's stage-gate system) was taught in a teacher-centred lecture, but rather detailed: 90 minutes combining simultaneous engineering and risk analysis. The alternative processes (agile project management, design thinking, open innovation and business model innovation) were only described by their main objectives and philosophies. Additional information was given then as a blended learning concept, on the e-learning platform. As it turned out - this was indeed an experiment - in every class at least one group chose one of the alternative processes, so that each course could participate of group work experience on e.g. 
design thinking or agile process management along with the traditional processes that have been taught. Moreover, every course experienced brainstorming, brainwriting, TRIZ or the Morphologic Box (or Morphologic Analysis) to generate ideas which allowed reflection of several methods in the context and in the group/ team. Assessment tuition was given to students by best practice examples as they performed the divergent and convergent thinking process. Some of the best outcomes were prototypes of a bottle opener, a paper tearing device for paper pads and a design concept of a ready-tobrew coffee maker.

Other methods that have been taught in teacher-centred lectures were portfolio analysis, risk analysis and methods of customer/ user integration (observation, interviews, customer tests, workshops, focus groups, field tests, Delphi and Lead-user method) - of which some were included in the later questionnaire for the survey.

\section{CONTEXT OF THE SURVEY}

The second year bachelor course consists of half a year business experience and the third year bachelor courses of a year. 67\% of the master students have more than five years of business experience, $33 \%$ between three and five-years business experience. Therefore, the survey allows to evaluate the results in dependency of business experience and educational level.

The survey was carried out in two phases. In phase one a questionnaire was setup and personally distributed the second year bachelor course. The completion of the survey was anonymous. $86 \%$ of students (30 out of 36) attended the survey. The survey was then analysed. Some formal adaptions to the questionnaire were corrected.

In phase two the survey was rolled out online to the two third year bachelor courses and the master course. The overall participation quota is $61 \%$, as the online participation is just below $60 \%$ in the third-year courses and unfortunately only $33 \%$ in the master course.

The students work during their study programme in companies: There is a good mixture of company sizes represented: 53\% with over 1000 employees, 39\% midsized companies and $8 \%$ of small companies with up to 50 employees

Approximately 90 percent of students answered that their company works in interdisciplinary teams. $61 \%$ of the students thought that their company processes are structured and defined, $36 \%$ thought of the processes only being partly structured and defined. Here especially companies up to 250 employees seem to perform poorly while the rest have a share of $65 \%$ to $73 \%$ structured and defined processes.

The survey then tries to clarify how many companies use the traditional development processes according to VDI2221 or stage-gate system (Cooper). $50 \%$ of the companies use the traditional processes in over $70 \%$ of their projects. The bigger the company the higher the percentage. Customer and user integration is realised in $98 \%$ of the companies. Moreover 60 to $70 \%$ of the companies use alternative process management systems, such as open innovation, agile project management (e.g. Scrum) and design thinking. Even $90 \%$ of the companies consider employee-initiated projects.

\section{RESULTS OF THE SURVEY}

The survey asks students to evaluate methods, the grade of gained knowledge (displeased, pleased, very pleased) and applicability "declaration to apply method" in industry, figure 3.

The participation rate (figure 3 top diagram) shows that only $55-58 \%$ of students that evaluated the methods (figure 3 bottom diagram) answered the detailed questions concerning applicability (figure 3 middle diagram) of the experienced methods, in particular brainwriting (635) and TRIZ, and other methods (details on methods in footnote of figure 3). $82 \%$ of students answered the detailed questions to well-known methods, in particular brainstorming and morphologic box, that have also been taught in other lectures and which are more often applied in the departments of their companies which was also questioned. A study carried out by Geschka and Dahlem [6] confirms the latter point.

The reason for the high shares on applying the creativity methods can be considered to have a relation to the lecture concept. The creativity methods brainwriting and TRIZ that have been applied in exercises and therefore experienced are rated exceptionally high with $91 \%$ of students willing to apply the methods in next projects and in their companies, shown in the middle diagram of figure 3 "declaration to apply method".

While only $58 \%$ of the students that participated declare to apply the creativity methods brainstorming and morphologic box, only $27 \%$ of the students declare to apply the other methods which were all 
taught in teacher-centred lectures. The latter result shows that students of design engineering seem to favour creativity methods. This may be as these methods foster their main tasks as design engineers. Nevertheless, these results show that teaching the other methods should be conceptually optimised.

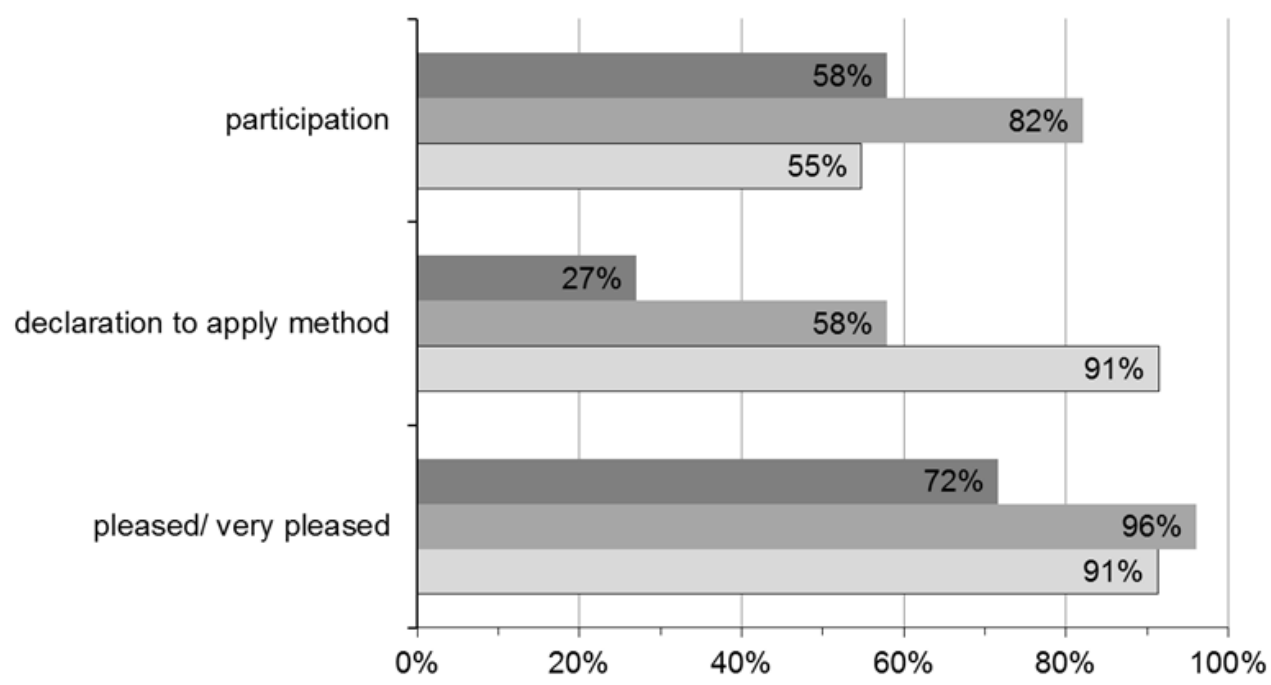

other methods (teacher-centered learning): e.g. portfolio analysis, risk analysis, benchmark, customer integration creativity methods (teacher-centred learning): brainstorming, morphologic box creativity methods experienced in exercises (student-centred learning): brainwriting (635), TRIZ

\section{Figure 3. Creativity methods, lecture concept vs. other methods}

The high rate of declaration to apply the experienced creativity methods (student-centred learning) show that exercises and experience gained through applying the methods helps the students to be willing to apply the methods in projects and in their companies. Best evaluated are the creativity methods: The bottom diagram in figure 3 shows that over $90 \%$ of all students taking part in the survey were pleased or very pleased with the gain of knowledge concerning the creativity methods, with only $5 \%$ difference whether the methods were experienced (student-centred learning) or taught in a teachercentred lecture. Even $72 \%$ of all students participating the survey were pleased or very pleased with learning about the other methods, though taught teacher-centred. This shows that students may be pleased or even very pleased with the lecture and their gain in knowledge, though applicability may not be supported (figure 3, bottom diagram versus middle diagram).

Finally, the students were asked to evaluate the overall concept of the lecture. The students evaluated the lecture concept with the following average grade in a grade system from 1 being poor to 5 being best:

- $\quad$ Traditional lecture (teacher-centred learning): 3.2

- $\quad$ Experience by exercise with practical examples (student-centred learning): 4.1

- Group/team work (student-centred learning): 4.0

- Blended learning: 3.0 in bachelor courses/3.5 in master course

Experience by exercises and group work (student-centred learning) have been clearly evaluated almost one grade better than the traditional lecture. In the evaluation of blended learning there is a polarisation to be found in the classes. There are students that really liked the blended concept, others rather said that they missed on contents, e.g. script and lecture notes. A lot of students rather liked the e-learning platform because all the information to a lecture is found there in one place. From the survey the concept of blended learning can clearly be optimised. The information for the bachelor classes in the e-learning platform was modest compared to the master course. The master course had access to additional lecture notes, a photo documentation of the group work and the script. They evaluated blended learning with 3.5. Finally, the survey recognisable does not reveal - and this may be the overall effect - that blended learning concepts have the effect that students have to "pull" their information not only out of a lecture they visit but also actively from the e-learning platform. To bring it to the point: blended learning requires additional work and learning effort by the students. And naturally some will profit and some will complain of additional or extra work. 


\section{SUMMARY}

The survey clearly shows that engineering students have gained knowledge over a wide range of different methods and processes in the lecture. Students highly consider application of creativity methods in industry, especially when these methods were experienced in exercises and group work (student-centred learning): in average over $90 \%$ of students declare to apply the creativity methods. Methods that have been taught in a traditional way in a teacher-centred lecture are only considered for application in a low range of less than $30 \%$. This seems to foster that students have not experienced the benefits of these methods although they have evaluated the gain of knowledge concerning these methods rather high $(72 \%)$.

An earlier study [10] that evaluated the ideas the participants had generated during the application of the brainwriting method showed, that the bachelor students (novices) generated almost as many ideas as the more experienced master students but the novices tend to develop concepts, that were often replications of existing ideas. The master students group created more diverse solutions but often less in quantity. The more experienced group benefits from additional material (e.g. heuristics) that was given, while the novice group (B.Eng. Students) didn't use this additional material during the brainwriting sessions.

Blended learning means a change of mindset, not only for lecturers, but specially also for the students. Those that thought to get all the information in class will have to learn that they also have to "pull" information additionally from the e-learning platform - and elsewhere (literature, internet). They're directed to search for information - and this brings us back to support self-initiated learning.

The lecturer is asked to setup a concept that considers all aspects, traditional lecture (teacher-centred), experience exercises (student-centred), group work, laboratory pre- and post-work etc. in combination with blended learning (possibilities). The challenge is to develop an interacting lecture concept from only serving information to a concept in which students actively participate, collaborate in teams, "pull" or search information and experience lecture contents to gain on "self-experienced" knowledge. The evaluation of the e-learning content clearly shows improvement potential: Lecture notes, photos of sketches and group work results but also feedback towards the exercises and group work will be future optimisation tasks.

\section{REFERENCES}

[1] Sauer T., Voß M., Bozkurt H. and Nutzmann M. Experiences with direct product-feedback in courses on Engineering Design. E\&PDE, 20th Int. Conf. on Engineering and Product Design Education. Institution of Engineering Designers. The Design Society. London. England. 2018.

[2] VDI-Richtlinie 2221. Methodik zum Entwickeln und Konstruieren Technischer Systeme und Produkte. (Methods for Engineering Design and Development of technical systems and products). Düsseldorf. VDI Verlag. 1993.

[3] Cooper R.G. Winning at new products - creating value through innovation. 4th edition; Basic Books. New York. USA. 2011

[4] Rohrbach B. Kreativ nach Regeln - Methode 635, eine neue Technik zum Lösen von Problemen. (Creative by rules - Method 635, a new technique for solving problems). Absatzwirtschaft 12, Nr. 19, 73-75. 1969.

[5] Geschka H., Schaude G. and Schlicksupp H. Methoden und Organisation der Ideenfindung in der Industrie. (Methods and organisation of idea generation in industry). Frankfurt. 1971.

[6] Geschka H. and Dahlem S. Kreativitätstechniken und Unternehmenserfolg. (Creativity techniques and success in companies). technologie \& management. Jg. 45, H 3, 106-110, 1996.

[7] VanGundy A.B. Brain Writing for new product ideas: An alternative to Brainstorming. Journal of Consumer Marketing, 1, No. 2, 67-74. 1984.

[8] Schröer B., Kain A. and Lindemann U. Supporting creativity in conceptual design: Method 635Extended. Design 2010. Dubrovnik, Croatia. 2010.

[9] Rustler F. Denkwerkzeuge der Kreativität und Innovation. (Creativity and Innovation ThinkingTools). 8th edition. Midas Management Verlag. St. Gallen. Zürich. 2018

[10] Voß M., Sauer T. and Bozkurt H. Using heuristics in idea generation: Does it take expertise to benefit? E\&PDE, Int. Conf. on Engineering and Product Design Education. Institution of Engineering Designers. The Design Society. London. England. 2014. 